Article

\title{
Biodegradable Hydrogels: Evaluation of Degradation as a Function of Synthesis Parameters and Environmental Conditions
}

\author{
Chiara Turioni ${ }^{1}$, Giacomo Guerrini ${ }^{1,2}$, Andrea Squartini ${ }^{3}\left(\mathbb{D}\right.$, Francesco Morari ${ }^{3}\left(\mathbb{D}\right.$, Michele Maggini ${ }^{1, *}$ \\ and Silvia Gross ${ }^{1, *}$
}

1 Dipartimento di Scienze Chimiche (DiSC), Università degli Studi di Padova, Via Marzolo 1, I-35131 Padova, Italy; chiara.turioni@unipd.it (C.T.); Guerrini@bioshydrogel.com (G.G.)

2 Bios Hydrogel srl, Via Trieste31/a, 35121 Padova, Italy

3 Dipartimento di Agronomia, Animali, Alimenti, Risorse Naturali e Ambiente (DAFNAE), Università degli Studi di Padova, Via dell’Università 16, I-35020 Legnaro, Italy; squart@unipd.it (A.S.); francesco.morari@unipd.it (F.M.)

* Correspondence: michele.maggini@unipd.it (M.M.); silvia.gross@unipd.it (S.G.)

Citation: Turioni, C.; Guerrini, G.; Squartini, A.; Morari, F.; Maggini, M.; Gross, S. Biodegradable Hydrogels: Evaluation of Degradation as a Function of Synthesis Parameters and Environmental Conditions. Soil Syst. 2021, 5, 47. https://doi.org/ 10.3390 /soilsystems 5030047

Academic Editor: Adriano Sofo

Received: 30 June 2021

Accepted: 10 August 2021

Published: 15 August 2021

Publisher's Note: MDPI stays neutral with regard to jurisdictional claims in published maps and institutional affiliations.

Copyright: (C) 2021 by the authors. Licensee MDPI, Basel, Switzerland. This article is an open access article distributed under the terms and conditions of the Creative Commons Attribution (CC BY) license (https:// creativecommons.org/licenses/by/ $4.0 /)$.

\begin{abstract}
The development of functional materials that promote the infiltration and retention of water and the controlled release of fertilizers and nutrients in soil is of interest in agriculture. In this context, hydrogels, three-dimensional polymeric structures able to absorb high amounts of water in their swelling process, play an important role. The swelling ability of hydrogels depends on their crosslinking: the higher the crosslinking degree, the higher the number of interactions in the structure, the lower the swelling response. In this work, we describe biodegradable hydrogels composed of natural feedstocks: cellulose, clay minerals, and humic acids, designed to (i) protect, hydrate, and help germinating seedlings to root even in unfavorable conditions; (ii) sustainably contribute to soil fertility in terms of moisture and nutrients; and (iii) act as a nutritive and protective coating for the seeds. Upon assessing the correlations between curing process and swelling degree (SW), we evaluated the degradation of new biodegradable hydrogels as a function of the synthesis parameters (swelling degree and composition) and environmental conditions (type of soil and water amount for the hydration of the hydrogels). The term curing is hereafter referred to the operation of baking the ingredients at given combinations of time and temperature to obtain a dry hydrogel. The results show that the environmental parameters considered, i.e., amount of hydration water and physical and chemical properties of the soil, play a more decisive role in determining the stability of these hydrogels in soil than their synthesis parameters, such as the composition and the swelling degree.
\end{abstract}

Keywords: conservative agriculture; cellulose; humic acid; clay; swelling; crosslink

\section{Introduction}

In the last century, the worldwide population has increased dramatically, with a consequent increase in food and primary resources demand. In an attempt to satisfy this growing need, uncontrolled exploitation of the farmlands began, which led to the development of more productive but also less sustainable agricultural systems [1]. Farming activities and intensive agriculture have caused a worrisome decrease in intrinsic fertility of farmlands worldwide, requiring ever-increasing costly inputs, which also require nonrenewable energies expenditure and generate undesirable environmental drifts in terms of eutrophication from inorganic nutrients runoff and greenhouse gases emissions. Every year, millions of hectares of land become non-productive because agriculture activities are becoming less sustainable, triggering degenerative soil processes [2]. In order to mitigate these problems, it is necessary to develop innovative solutions capable of promoting new forms of agriculture, featuring minimal soil disturbance and enhancing soil conservation. In the socio-economic context described above, research is evolving to develop new materials 
and strategies that can promote the achievement of the conservation agriculture aims and, from a more practical point of view, (i) the infiltration and retention of water in soils, (ii) soil aggregates formation, and (iii) the controlled release of fertilizers and/or nutrients. Among the most promising materials, particularly interesting are the super-adsorbent hydrogels (SAHs). SAHs are three-dimensional polymeric structures that, due to the presence of hydrophilic functional groups, absorb and retain large amounts of water or water solutions through a spontaneous swelling process [3]. The interest from different production sectors in SAHs led to the design of a wide variety of hydrogels with different physical, chemical, structural, and functional properties for specific applications [4,5]. SAHs can be classified according to the mentioned properties [6] and one of the possible classifications concerns the type of crosslinking present between the polymeric chains [6]:

- chemical crosslinking: covalent bonds formation [7] through the application of radiations or addition of chemicals also in conjunction with the use of heat [8];

- physical crosslinking: weak bonds formation (hydrogen or electrostatic interactions) [7].

The ability of a hydrogel to absorb and retain water or water solutions depends on the type and extension of the crosslinking that forms the hydrogel [8] and on external parameters, such as the $\mathrm{pH}$ and ionic strength of the solution. This absorption process causes swelling, quantified as swelling degree (SW).

A different classification is based on the chemical composition of hydrogels [8]. This allows the identification of:

- $\quad$ hydrogels based on synthetic polymers;

- hydrogels based on natural polymers;

- $\quad$ hybrid hydrogels (based on both synthetic and natural polymers).

Among natural hydrogels, those composed of polysaccharides (e.g., cellulose) are particularly relevant because they are: (i) biodegradable, (ii) low cost, (iii) non-toxic, (iv) renewable, and (v) easy to fabricate from readily available precursors [9].

The hydrogels studied in this work can be identified not only as natural but, rather as pedogels: hydrogels composed of substances naturally present in the soil (cellulose, clay minerals, and humic acids). The combination of inorganic components, such as clays, characterized by a lamellar and compact structure, and organic matter, such as cellulose and humic acids, infiltrating between the clay layers, is the process that leads to the formation of the functional structure of a soil in nature. This results in the formation of aggregates with pores, which allow the infiltration of gas and water to sustain life growth. The main idea behind the development of these hydrogels is to mimic the soil composition, to blend seamlessly into the target soils, and to promote and possibly accelerate the formation of their functional structure wherever it had been degraded by intensive agricultural disturbances.

As already mentioned, the main components of the hydrogels hereby examined are:

- cellulose derivatives (carboxymethyl cellulose sodium salt ( $\mathrm{NaCMC}$ ));

- clay mineral (sodium bentonite);

- humic acids sodium salt (AHum).

Cellulose, a widespread organic molecule in nature, is composed of two glucose molecules bound with $\beta(1 \rightarrow 4)$ glycosidic bonds, and the repeated unit is cellobiose. The linear chains of cellulose can create intra- and intermolecular hydrogen bonds to join and interact with one another, causing an increase in the mechanical resistance of the chains [10].

Cellulose presents many different advantages in hydrogel production, such as biodegradability, low cost, ease of availability, non-toxicity, and renewability. All these advantages can be also found in many cellulose derivatives: hydroxypropyl methylcellulose (HPMC), carboxymethyl cellulose sodium salt (NaCMC), hydroxyethyl cellulose (HEC), ethylcellulose (EC), and methylcellulose (MC) [3]. The main component of the hydrogel hereafter described is an insoluble cellulose derivative: the carboxymethyl cellulose sodium salt ( $\mathrm{NaCMC})$, chosen to ensure a flexible structure to the hydrogels that allows the swelling of the material while avoiding its dissolution when in contact with water or water solutions. 
Due to its polyelectrolyte characteristics, this cellulose derivative allows the production of hydrogels characterized by high swelling ability [3]. This is due to the charges present on the polymer macromolecule; in particular, there are different effects on which the swelling process is based: (i) osmotic pressure: the charges present in the molecules are unable to leave them and, therefore, they attract water inside the hydrogel [3]; (ii) the electrostatic repulsion that can be established between carboxylated residues since they are negatively charged and favor the elongation and spacing of the polymer chains occurring during swelling [3]; and (iii) the Gibbs-Donnan effect generated by the presence of positive counterions in the structure in order to ensure neutrality $[3,11]$. The second main component of the formulation hereby presented is sodium bentonite, a phyllosilicate clay composed of different components: montmorillonite, at a high percentage; and kaolinite, mica, and illite at lower percentages [12]. The role of this component in the hydrogels is to strengthen the $\mathrm{NaCMC}$ structure and to confer resistance against external agents such as dehydration and degradation mediated by different factors.

Silicates are structures composed of silicon and oxygen atoms that form tetrahedral units $\left[\mathrm{SiO}_{4}\right]^{4-}$, which can create different structures based on their disposition. In the aluminosilicates, $\mathrm{Si}^{4+}$ ions are partly replaced with $\mathrm{Al}^{3+}$ ions. Aluminosilicates are characterized by a lamellar and porous shape that is fundamental in determining the physical and chemical properties of these clays [13]. An important feature of these structures is the presence of metal cations $\left(\mathrm{Ca}^{2+}, \mathrm{K}^{+}\right.$, and $\left.\mathrm{Na}^{+}\right)$intercalated between the tetrahedral layers, in the zone called the tunnel or inter-layer, which play the role of neutralizing the negative charge of the structure generated by the $\mathrm{SiO}_{4}{ }^{4-}$ ions [14]. These ions can be exchanged with other counter ions (e.g., $\mathrm{Ca}^{2+}$ ), but the presence of $\mathrm{Na}^{+}$between two tetrahedral layers increases the absorption ability of bentonite [12], making it optimal for the production of highly swellable hydrogels.

An important parameter describing phyllosilicates is their cationic exchange capacity (CEC), defined as the milliequivalents of monovalent cations exchanged by $100 \mathrm{~g}$ of dehydrated clay. The CEC value for smectite, the family of clays to which montmorillonite belongs, is within the range of $80-150$ milliequiv / $100 \mathrm{~g}$ [15]. Some studies proved that the addition of bentonite to soil can positively affect it and its ecosystem; for example, it can be used as soil conditioner to increase the water retention ability of the soil [16], an important feature for agricultural fields whose physical and chemical properties are unfavorable to water retention.

Humic substances are a stock of stabilized organic carbon in soil derived from the chemical and biological degradation and re-synthesis process of organic matter, of both plant and animal origin, mediated by microorganisms [17]. Humic substances can be classified on the basis of the $\mathrm{pH}$ range in which they appear to be soluble in water [18]. These substances are thought to be essential for several processes that occur in the soil: they were reported to putatively promote the growth of plants [17], the absorption of nutrients by plants, root development, and structural stability of the soil [19]. The component used for the production of the hydrogels here-described is a humic acid sodium salt (AHum), characterized by various functional groups (alcoholic, aldehyde, and carboxylic acid derivatives) and chosen to favor the crosslinking process and therefore a crosslinking internal hydrogel.

In this study, three soil samples of very different types were tested to determine the effects of their physical, chemical, and biological properties on the stability of the hydrogels. In particular, a floodplain valley soil sample (agricultural soil), a coastal soil sample, and a mountain soil sample (beech forest soil) were chosen. The first two are soils that have been exploited for centuries for agriculture, while the mountain broadleaf forest soil represents a human-managed, low-impact climax ecosystem. Within these choices, to investigate the expectedly high impact of the water amount used to hydrate the hydrogels on their stability, different soil moisture levels were tested on each soil. The aim of these experiments was to determine how the target soil properties affect the degradation of hydrogels formulated with different contents of humic acids and different $\mathrm{SW}_{24}$. The trials were conducted 
by mimicking the different environmental parameters (rainfall) occurring in the regions of origin of each soil as accurately as possible in order to predict the behavior of these materials in different agroclimatic conditions.

\section{Materials and Methods}

\subsection{Chemicals}

Carboxymethyl cellulose sodium salt, high viscosity (NaCMC, CAS 9004-32-4), humic acids sodium salt (AHum, technical grade, CAS 68131-04-4), and hydrochloric acid (37\%, CAS 7647-01-0) were purchased from Sigma Aldrich (Sigma-Aldrich, St. Louis., MO, USA). Sodium bentonite (clay) was purchased from Oenofrance (Oenofrance, Montebello Vicentino, Italy).

The soil samples used in this work were: a coastal soil (Parco dell'Uccellina, Grosseto (GR), Tuscany, Italy), beech forest soil (Monte Bondone, Trento (TN), Trentino Alto Adige, Italy), and agricultural soil (Legnaro, Padova (PD), Veneto, Italy). Per the World Reference Base for Soil Resources (WRB), these fall within the Cambisol, Histosol, and Fluvisol categories, respectively.

In Table 1, the chemical compositions and properties of the tested soils are reported.

Table 1. Soil samples tested: chemical composition and properties.

\begin{tabular}{|c|c|}
\hline Soil Sample & Description \\
\hline Agricultural soil & $\begin{array}{c}\text { pH } 8.1 \\
\text { Organic carbon } 0.6 \% w / w \\
\text { Total nitrogen } 0.09 \% w / w \\
\text { Organic C/N: } 6.7 \\
\text { Olsen } \mathrm{P}_{2} \mathrm{O}_{5}: 0.18 \% w / w \\
\text { Texture: sand: } 35 \% ; \text { silt: } 48 \% \text {; clay: } 17 \% \\
\text { Electrical conductivity: } 0.145 \mathrm{mS} / \mathrm{cm}\end{array}$ \\
\hline Beech forest soil & $\begin{array}{c}\mathrm{pH} 6.6 \\
\text { Organic carbon } 6.73 \% w / w \text { (humic carbon } 4.22 \% \text { ) } \\
\text { Total nitrogen: } 0.53 \% w / w \\
\text { Organic C/N: } 12.7 \\
\text { Olsen } \mathrm{P}_{2} \mathrm{O}_{5}: 0.26 \% w / w \\
\text { Texture: sand: } 55 \% \text {; silt: } 22 \% \text {; clay: } 23 \% \\
\text { Electrical conductivity } 0.112 \mu \mathrm{S} / \mathrm{cm}\end{array}$ \\
\hline Coastal soil & $\begin{array}{c}\text { pH } 7.8 \\
\text { Organic carbon } 1.52 \% w / w \\
\text { Total nitrogen } 0.17 \% w / w \\
\text { Organic C/N: } 8.8 \\
\text { Olsen } \mathrm{P}_{2} \mathrm{O}_{5}: 0.16 \% w / w \\
\text { Texture: sand: } 34 \% \text {; silt: } 23 \% \text {; clay: } 43 \% \\
\text { Electric conductivity: } 0.375 \mathrm{mS} / \mathrm{cm}\end{array}$ \\
\hline
\end{tabular}

\subsection{Hydrogel Synthesis Protocol}

The synthesis of the biodegradable hydrogels studied in this work is described in the flow diagram in Figure 1. 


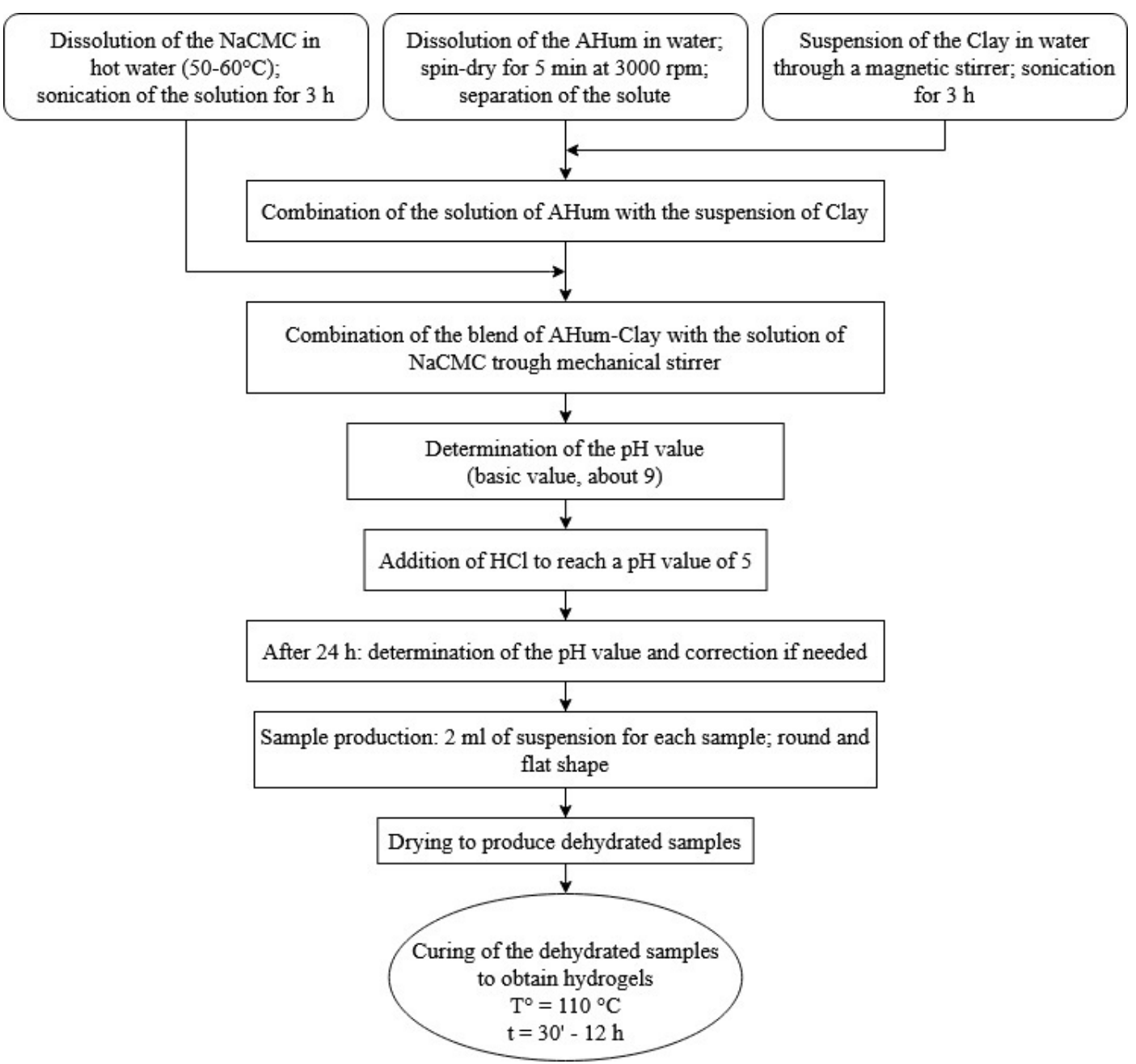

Figure 1. Flow diagram for the preparation of the hydrogels.

Hydrogels Preparation: General Procedure

A $2.5 \% w / w$ stock solution of $\mathrm{NaCMC}$ in water was prepared by pouring $\mathrm{NaCMC}$ in deionized water at $50-60{ }^{\circ} \mathrm{C}$ under mechanical stirring. Residual lumps were removed by treating the mixture in an ultrasonic cleaning bath for $3 \mathrm{~h}$ at room temperature. A stock solution of AHum in deionized water was prepared by adding water to solid AHum under stirring until dissolution. The mixture was centrifuged ( $5 \mathrm{~min}$ at $3000 \mathrm{rpm}$ ) to remove residual particulate matter/ this solution, after drying a known volume in an oven at $100{ }^{\circ} \mathrm{C}$ for $2 \mathrm{~h}$ and weighting the solid residue, was $5 \% \mathrm{w}$ AHum/w water. An $8 \% w / w$ stock suspension of clay in deionized water was obtained by adding water to the clay under mechanical stirring and sonicating the resulting mixture for $3 \mathrm{~h}$. The concentrations of $\mathrm{NaCMC}$ and clay stock solution were confirmed by drying a known volume and weighting the solid residue, as described for AHum. Aliquots from each stock solution were combined (see Section 2.4 for the specific formulations), the $\mathrm{pH}$ adjusted to 5 , and the resulting mixture left at room temperature in a capped vessel. After $24 \mathrm{~h}$, and a further $\mathrm{pH}$ correction to 5 if needed, $2 \mathrm{~mL}$ of each specific formulation was evaporated in a ventilated hood at ambient pressure and temperature, and the solid residue was cured in an oven as described in Table 2. 
Table 2. Hydrogels tested and experimental conditions of the curing parameters.

\begin{tabular}{|c|c|c|}
\hline Suspension & Curing Temperature & Curing Times \\
\hline $50_{(10)}-5$ & $110^{\circ} \mathrm{C}$ & $1,3,5,7,9$, and $12 \mathrm{~h}$ \\
\hline $50_{(30)}-5$ & $110^{\circ} \mathrm{C}$ & $\begin{array}{c}30 \text { min; } 2 \text { h; } 3 \text { h } 30 \text { min; } 5 \text { h; } \\
6 \text { h } 30^{\prime} \text { min; } 7 \text { h; } 7 \text { h } 30 \text { min; } 12 \text { h }\end{array}$ \\
\hline $50_{(50)}-5$ & $110^{\circ} \mathrm{C}$ & $\begin{array}{c}30 \text { min; } 1 \text { h; } 1 \text { h } 30 \text { min; } 2 \text { h; } \\
2 \text { h } 30 \text { min; } 3 \text { h } 30 \text { min; } 4 \text { h } 30 \text { min; } \\
5 \text { h } 30 \text { min; } 6 \text { h } 30 \text { min; } 7 \text { h; } 7 \text { h } 30 \text { min; } 12 \text { h }\end{array}$ \\
\hline
\end{tabular}

Figure 2 reports the nomenclature used to identify each suspension from which the hydrogels were fabricated.

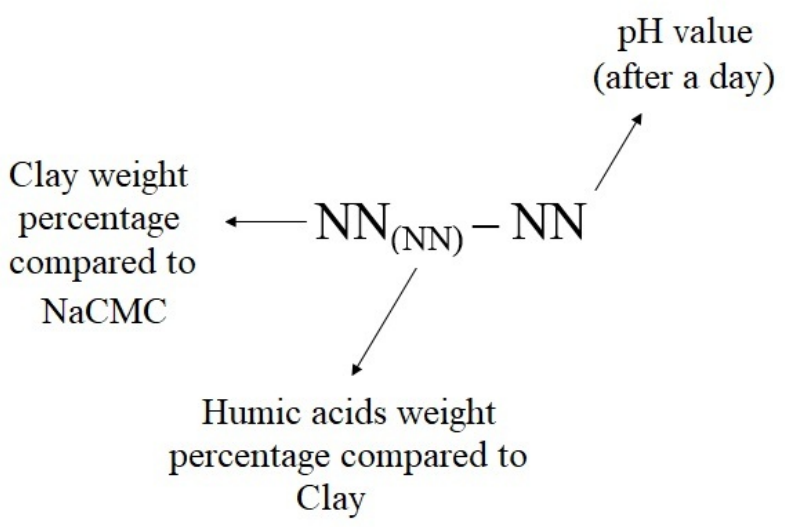

Figure 2. Nomenclature of the hydrogel suspensions.

\subsection{Degradation Analysis Systems}

The degradation of the reported hydrogels was analyzed with specific homemade devices that allow a non-direct contact between hydrogels and soil. These devices consisted of:

- Two $50 \mathrm{~mL}$ Falcon tubes perforated on the bottom: the upper one with a larger hole to facilitate the introduction of deionized water, and the lower tube with many narrower holes to avoid any leakage of soil when present and to allow the water percolation;

- 2 Falcon caps from which the upper part was removed to allow the positioning of the discs of synthetic fabric;

- 2 discs of synthetic fabric with fine mesh $\left(900\right.$ holes per $\left.\mathrm{cm}^{2}\right)$ placed in the upper part of each Falcon and held in place by the caps of the tubes;

- 1 square of absorbent paper crumpled and placed on top of the synthetic fabric in the upper tube, used to avoid the passage of soil through the synthetic fabric;

- 1 square of absorbent paper crumpled and placed at the base of the lower Falcon to prevent the leakage of soil when present;

- rubber bands.

The hydrogel was placed in the cell formed between the two tubes in contact with the two discs of synthetic fabric to promote hydration with deionized water enriched with chemicals/microorganisms from the layer of soil placed in the upper tube. The two tubes were held together by a rubber band (green, Figure 3), which in turn was held in place by two other rubber bands (red, Figure 3). This configuration allowed the operator to open the system in the cell where the hydrogels were positioned (Figure 3b). 


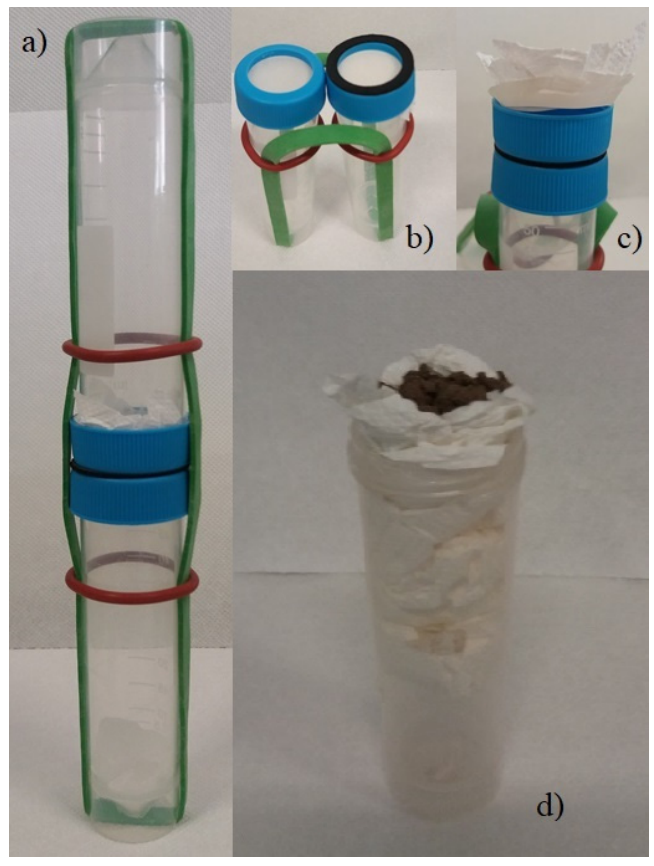

Figure 3. Degradation analysis systems: (a) complete system; (b) opened system showing the cell in which the hydrogel is inserted; (c) disposition of the synthetic fabric and piece of absorbent paper in the upper Falcon tube; (d) lower Falcon tube of the degradation analysis system with $4 \mathrm{~g}$ of soil and absorbent paper.

Then, the preparation process of the degradation analysis systems both for those filled with the soil samples and for the control is reported:

- Systems with soil sample: the upper Falcon tube was filled with $10 \mathrm{~g}$ of soil. In the lower tube a piece of absorbent paper was shaped like a bowl and $4 \mathrm{~g}$ of soil was put in it to ensure contact between the soil and the overlaying synthetic fabric. This arrangement was adopted to allow the drainage of the deionized water through the lower Falcon tube and to mimic the placement of the hydrogel in the soil;

- Control systems: the upper Falcon tube was filled with on sheet of absorbent paper and two were placed in the lower Falcon.

\subsection{Relationship Assessment between Curing Process and Swelling Degree $\left(\mathrm{SW}_{24}\right)$}

Three suspensions, differing in the humic acid (AHum) amount (i.e., $10 \%, 30 \%$, or $50 \% w / w)$ were studied. The amounts of $\mathrm{NaCMC}$ and clay were both of $50 \% w / w$ in each of the three suspensions.

For each suspension, several hydrogels with different curing times were produced and the $\mathrm{SW}_{24}$ value was calculated from triplicate samples (Table 2).

The weight of the dried hydrogels was recorded after the curing process (dried hydrogel weight), then a $24 \mathrm{~h}$ hydration process with $20 \mathrm{~mL}$ of deionized water was performed. After, the hydrogels were manually blotted with absorbent paper to remove the excess water, and the wet weights were recorded (swollen hydrogel weight).

As mentioned before, the absorption process causes swelling, quantified as swelling degree (SW), which is calculated as follows:

$$
\mathrm{SW}=\frac{\text { Swollen hydrogel weight }- \text { Dried hydrogel weight }}{\text { Dried hydrogel weight }}
$$

where the dried hydrogel weight is the weight of the hydrogel before hydration.

In this paper, the $\mathrm{SW}(\mathrm{x})$ of a specific hydrogel is reported as $\mathrm{SW}_{24}(\mathrm{x})$ to indicate the swelling degree after $24 \mathrm{~h}$ of immersion in a non-limiting amount of deionized water. 
The results reported hereafter are the average $\mathrm{SW}_{24}$ value obtained from three replicas.

\subsection{Degradation Analysis Experiments}

The effects of $\mathrm{SW}_{24}$, soil moisture level, and physical and chemical composition on the stability of the hydrogels were tested in triplicate samples in two degradation experiments. Two $\mathrm{SW}_{24}$ values were tested: $\mathrm{SW}_{24}(\sim 30)$ and $\mathrm{SW}_{24}(\sim 65)$, and the curing times to obtain them were extrapolated from the previous experiment. In Figure 4, the degradation analysis experiments scheme is reported.

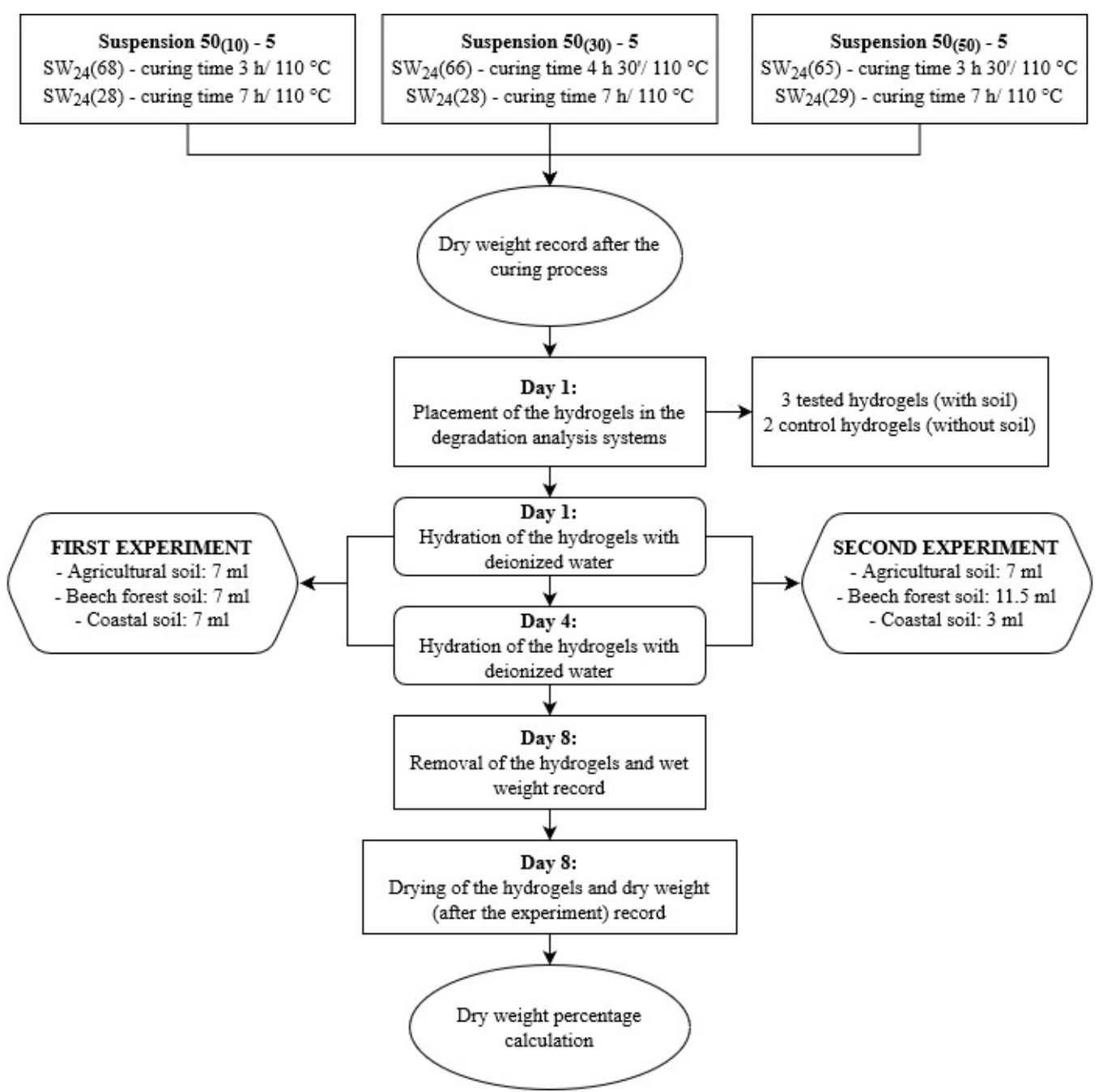

Figure 4. Degradation analysis experiments scheme.

In the first experiment, the same amount of deionized water was used to hydrate all the hydrogels (those treated with soil samples and the control hydrogel). The amount of deionized water to be added was calculated on the basis of the average 20 year monthly rainfall observed in May between 2000 and 2019 in each of the geographical areas of the three soils used in these experiments. In particular, the average monthly rainfall in May was used as the basis for calculation to hydrate the hydrogels twice. The aim was to investigate the effect of the $\mathrm{SW}_{24}$ value and the physical and chemical characteristics of the soil on the stability of the hydrogels, maintaining an equal amount of hydration water.

In the second experiment, the amount of water used for the hydration processes was the average May rainfall between 2000 and 2019 in each geographic area divided by 8 in order to hydrate the hydrogel twice during one week of experiment (a rainfall frequency of two times per week was assumed and a 1 week long experiment was performed. For 
this reason, we decided to divide the total amount of rainfall of May from 2000 to 2019 by 8 ). The aim was to associate to each soil sample the respective rainfall water amount in order to investigate the effect of different agroclimatic conditions on the stability of the hydrogels. Rainfall data were provided by ARPA Veneto, station 111, Legnaro (PD), for the agricultural soil; Meteotrentino, station T0368, Viote Monte Bondone (TN), for the beech forest soil; ad SIR Regione Toscana, TOS03003011 station, Poggio Perotto, (GR), for the coastal soil.

\section{Results and Discussion}

\subsection{Relationship between Curing Process and Swelling Degree $\left(S_{24}\right)$}

The dependency of $\mathrm{SW}_{24}$ from the curing process is described by a first-degree exponential decay (Figure 5) as follows:

$$
y=a-b * C^{x}
$$

This trend can be explained by an increase in the interactions inside the hydrogels caused by the prolonged heating, which leads to a reduction in the amount of water that a hydrogel can absorb. As shown in Figure 5, a higher data dispersion was observed at the lowest curing time. This is explainable by the hydrogels with higher $\mathrm{SW}_{24}$ being more difficult to handle because of their soft texture, which may have led to the loss of material during the drying process with absorbent paper. This material loss could lead to errors in the wet weight recording, causing high variation between the replicas' $\mathrm{SW}_{24}$ values.

Another important aspect is that even though the $\mathrm{SW}_{24}$ with short curing times was considerably different between the three suspensions analyzed $\left(\mathrm{SW}_{24}(115), \mathrm{SW}_{24}(185)\right.$, and $\left.\mathrm{SW}_{24}(109)\right)$, the $\mathrm{SW}_{24}$ of suspensions $\mathrm{SW}_{24}(19), \mathrm{SW}_{24}(24)$, and $\mathrm{SW}_{24}(22)$ with $12 \mathrm{~h}$ of curing was similar. This is a further indication of the relevance of the curing time. This parameter proved to exert an important effect on swelling properties. Swelling tended to be more similar after the point at which a certain low threshold of curing time was reached.

\subsection{Degradation Analysis Experiments}

Figure 6 reports the results of the first degradation experiment, in which the effect of the $\mathrm{SW}_{24}$ and the physical and chemical composition of the soil on the stability of the hydrogels were tested. The hydration water amount was the same for all soil samples and control hydrogels ( $7 \mathrm{~mL}$ per hydration process).

In Figure 6, the average percent dry weight is plotted against the $\mathrm{SW}_{24}$ value of the tested hydrogels. The standard deviation was calculated based on three replicates for the tested hydrogels and two replicates for the control hydrogels.

From Figure 6, it is possible to conclude that:

- No significant differences in the resistance to degradation appeared among any of the cases under examination at these SW24 values;

- Comparing the different soil treatments, the coastal soil treatment was found to be the least effective on hydrogels degradation in all the studied conditions; the agricultural soil treatment, conversely, was the most degrading one, as well as the only one that displayed statistically significant differences from the others in most of the conditions tested in terms of AHum percent concentration and gel curing time. 

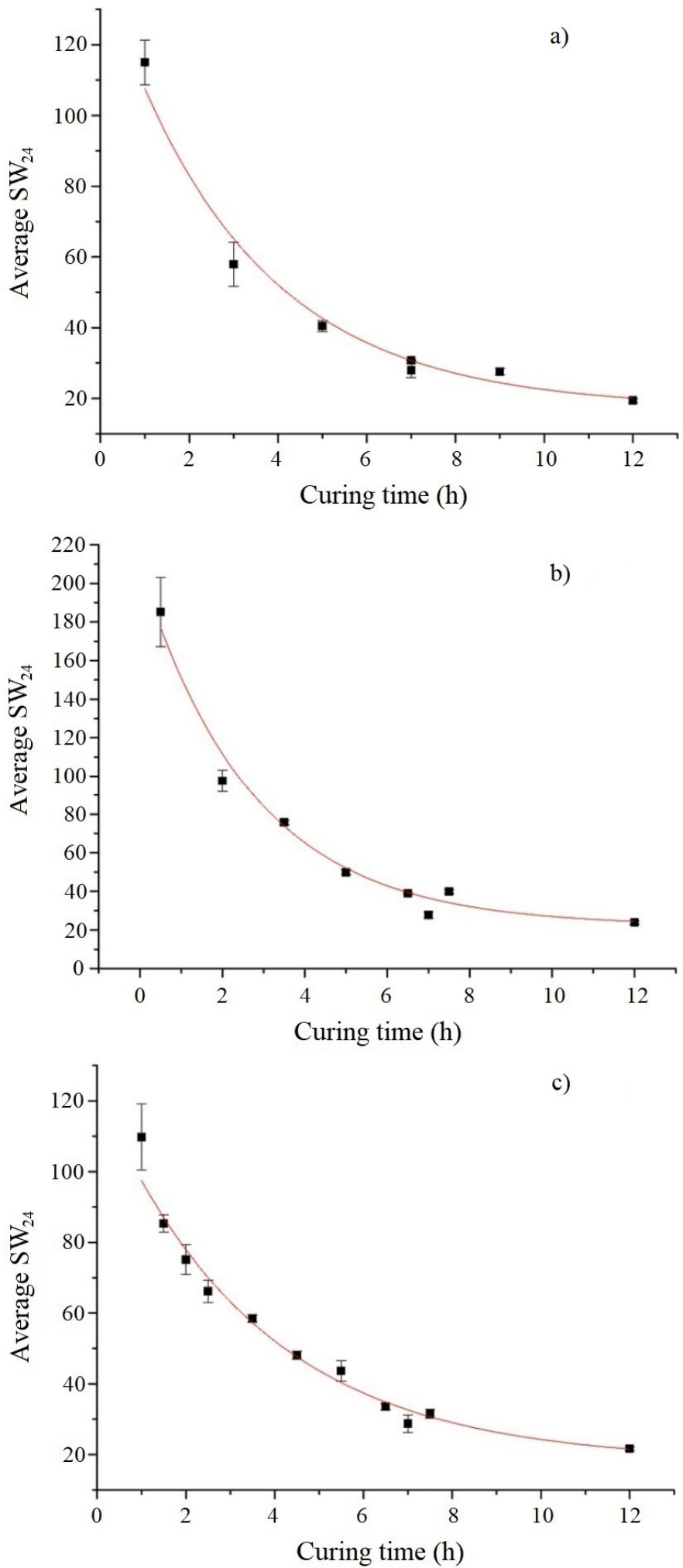

Figure 5. Correlation between curing time and swelling degree $\left(\mathrm{SW}_{24}\right)$ of the (a) $10 \% w / w$ AHum suspension; (b) 30\% w/w AHum suspension; (c) 50\% w/w AHum suspension. 


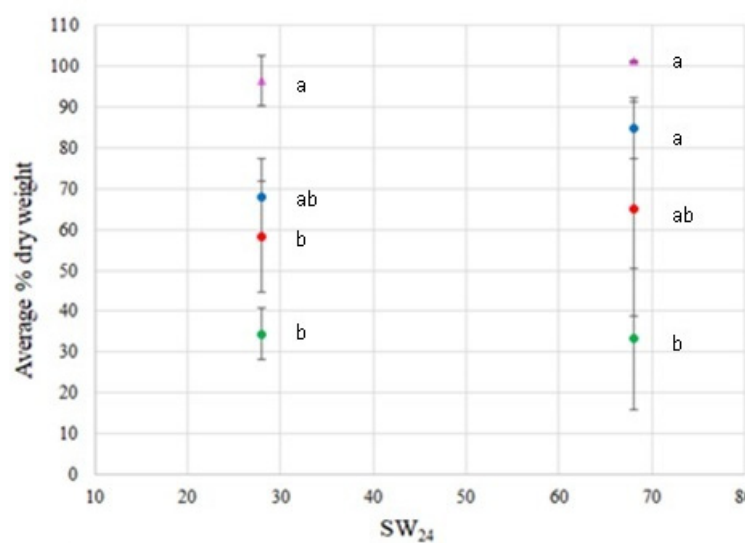

a)

$\triangle$ Control

- Coastal soil treatment

- Beech forest soil

treatment

- Agricultural soil

treatment

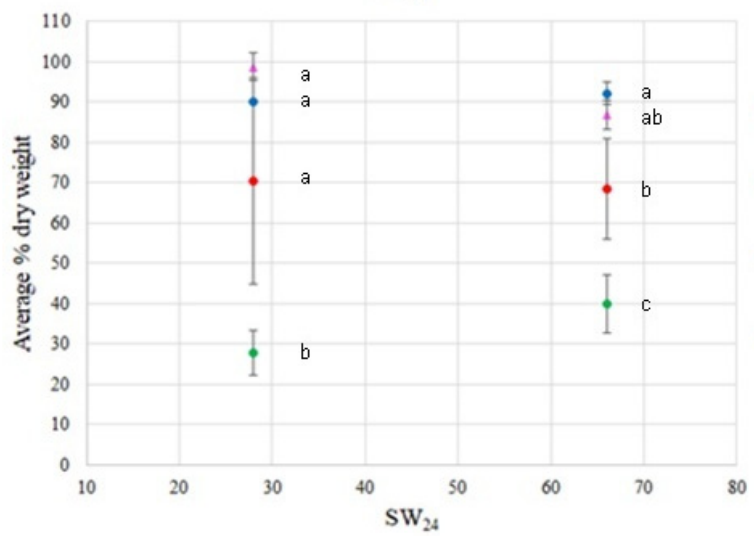

b)

4 Control

- Coastal soil

treatment

- Beech forest soil

treatment

- Agricultural soil

treatment

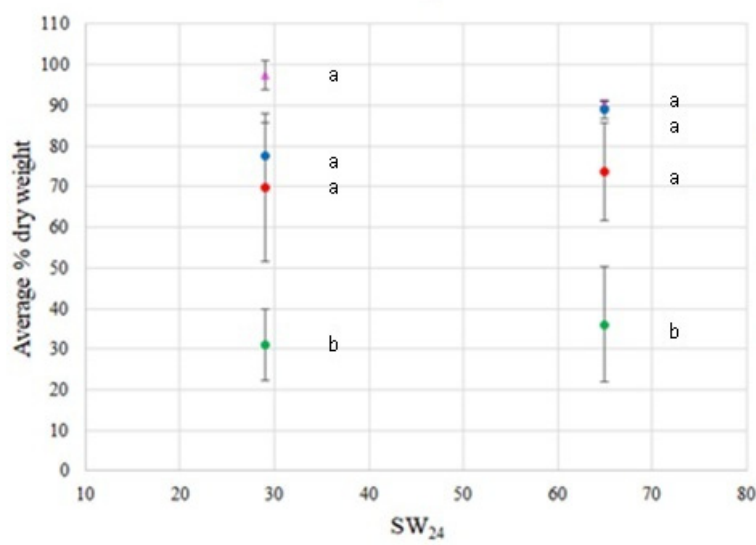

c)

4 Control

- Coastal soil

treatment

- Beech forest

soil treatment

- Agricultural soil

treatment

Figure 6. Average percentage dry weight at the end of the first degradation analysis experiment for the $\mathrm{SW}_{24}$ value analyzed for the (a) 10\% w/w AHum suspension; (b) 30\% w/w AHum suspension; (c) $50 \% w / w$ AHum suspension. Two different curing times, leading to two resulting $\mathrm{SW}_{24}$ values that are inversely proportional to the curing time values. Treatments sharing the same letter (within vertical comparisons) are not statistically significant for $p<0.05$ (ANOVA; Tukey's post hoc test). Bars presents mean value \pm standard deviation.

The results can be explained considering the carbon and nitrogen contents and the organic $\mathrm{C} / \mathrm{N}$ ratio that characterizes each soil sample tested (Table 1 ). Based on these features, it is possible to infer the following explanations:

- In the agricultural soil (organic $\mathrm{C} / \mathrm{N}$ ratio 6.7): the low $\mathrm{C} / \mathrm{N}$ ratio value, caused by the overexploitation of the soil, led to a mineralization of the nutrients (e.g., nitrogen). The low amount of organic matter present in this soil was supposedly the factor that led to the fast degradation of the studied hydrogels, which are made primarily of organic compounds. 
- In the beech forest soil (organic $\mathrm{C} / \mathrm{N}$ ratio 12.7 ), the higher $\mathrm{C} / \mathrm{N}$ ratio value is due to the cyclic yearly addition of organic matter (e.g., leaves) and its slow decomposition, which leads to an increase in the acidity of the soil. Both these factors can affect hydrogels degradation, in part by a competition between the organic matter already present in the soil and the hydrogels and in part by a general slowing of the degradation activities caused by the acidity of the soil. Nevertheless, this soil is, by constitution, pre-enriched in microorganisms able to degrade organic matter, which partly occurs and contributes to the second-place score of this soil.

- The coastal soil (C/N ratio 8.8), like the agricultural soil, was subjected to cropping, but contains a higher organic matter amount. Although the soil in its bulk does not feature a marked salinity (electrical conductivity (EC 5:1) $0.375 \mathrm{mS} / \mathrm{cm}$ ), its toplayer bacteria are prone to osmotic stress due to its location and the consequently frequent marine aerosols. This can slow the microorganisms' metabolism, making them incapable of degrading the organic matter and the hydrogels as fast as in the other soil samples, leading to the least degradative effect among all cases examined.

In Figure 7, results of the second degradation experiment, in which the effect of the $\mathrm{SW}_{24}$ and different simulated agroclimatic conditions on the stability of the hydrogels were tested, are reported. The hydration water amount was specific for each soil sample and the respective control hydrogels $(11.5 \mathrm{~mL}$ of deionized water were supplemented to both samples treated with the beech forest soil and the respective control hydrogels; $7 \mathrm{~mL}$ of deionized water were supplemented to both samples treated with the agricultural soil and the respective control hydrogels; $3 \mathrm{~mL}$ of deionized water were supplemented to both samples treated with the coastal soil and the respective control hydrogels). In the graphs in Figure 7, the average percent dry weight is plotted against the $\mathrm{SW}_{24}$ value of the tested hydrogels. It is also shown the correlated error (standard deviation) calculated based on three replicas for the tested hydrogels and two replicas for the control hydrogels.

Comparing the different agroclimatic conditions tested:

- For both the agricultural and the beech forest soils, the degradation effect on the hydrogel was significantly higher than that observed in their respective controls at each of the AHum percentage concentrations and swelling values.

- The highest difference was displayed by the agricultural soil. For both agricultural and beech forest soils, the longer the curing time (corresponding to a lower swelling), the higher the degradation value.

- The treatment with the coastal soil showed no significant difference in comparison to its control in each of the combinations tested.

These analysis experiments highlighted, within the range of humic acids and $\mathrm{SW}_{24}$ hereby tested, the primary importance is the chemical and biological composition of the soil and the water amount received by the hydrogels. 
a)

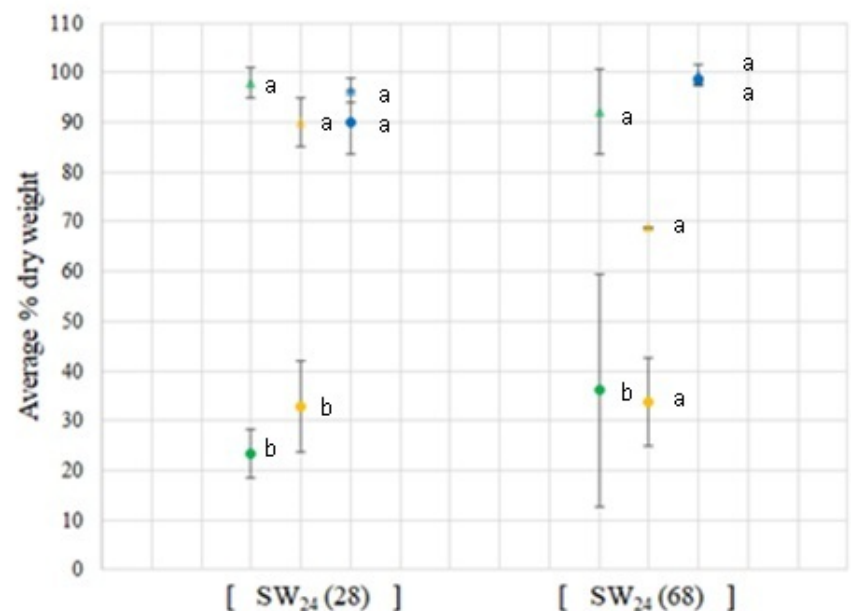

- Coastal soil treatment

Control (coastal soil treatmente)

Beech forest soil treatment

Control (beech

forest soil

treatment)

- Agricultural soil

treatment

Control (agricultural soil treatment)

b)

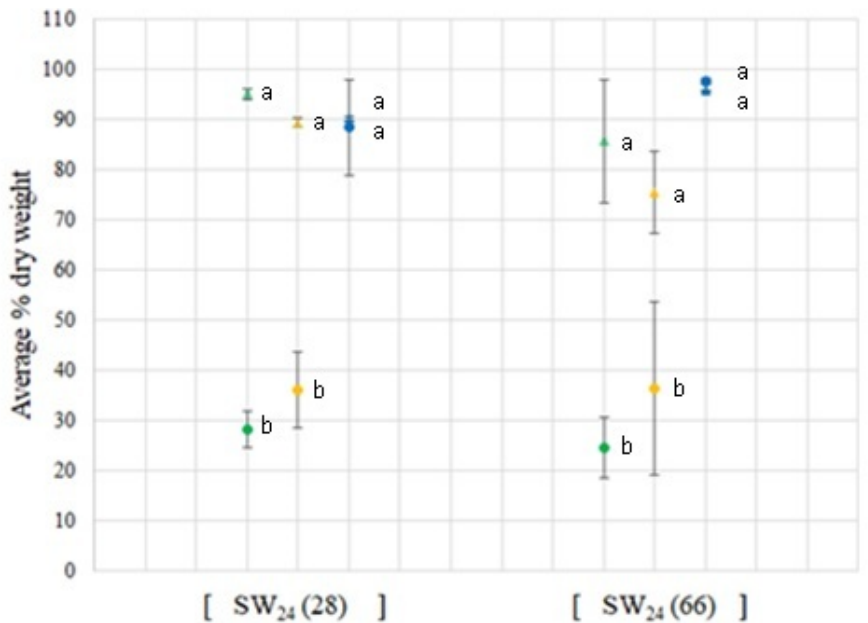

- Coastal soil treatment

4 Control (coastal soil treatment)

Beech forest soil treatment

\section{Control (beech}

forest soil

treatment)

- Agricultural soil treatment

4 Control

(agricultural soil treatment)

c)

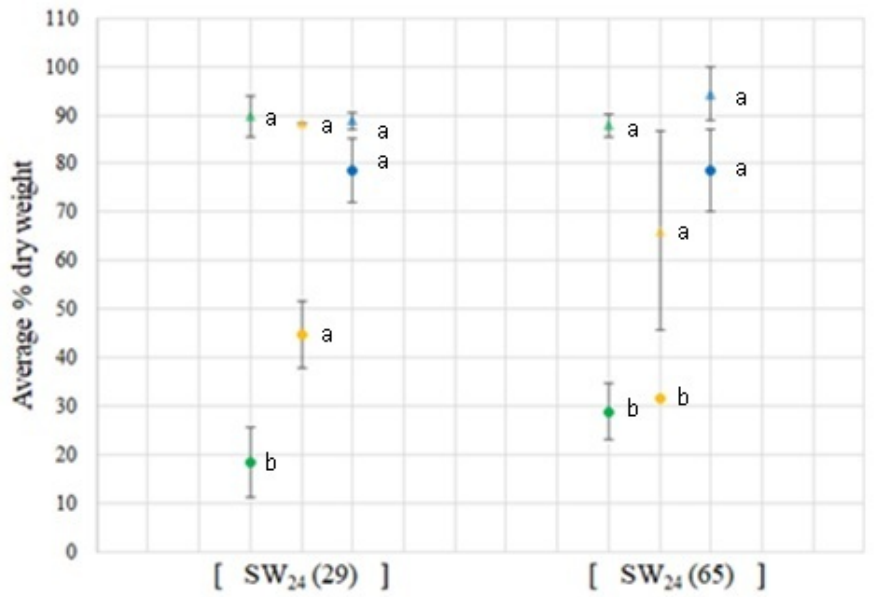

- Coastal soil treatment

- Control (coastal soil treatment)

- Beech forest soil treatment

Control (beech

forest soil

treatment)

- Agricultural soil treatment

- Control

(agricultural soil treatment)

Figure 7. Average percentage dry weight at the end of the second degradation analysis experiment for the $\mathrm{SW}_{24}$ value analyzed for the (a) $10 \% w / w$ of AHum suspension; (b) $30 \% w / w$ of AHum suspension; (c) $50 \% w / w$ of AHum suspension. Two different curing times, leading to two resulting $\mathrm{SW}_{24}$ values which are inversely proportional to the curing time values are shown. Treatments sharing the same letter (within vertical comparisons) are not statistically significant for $p<0.05$ (ANOVA; Tukey Post Hoc Test). Bars presents mean value \pm standard deviation. 


\section{Conclusions}

Upon examining the swelling degree $\left(\mathrm{SW}_{24}\right)$ and curing time of these new biodegradable hydrogels prepared starting from three different suspensions (same $\mathrm{NaCMC}$ and clay amount, different humic acid (AHum) amounts: 10\%,30\%, and 50\% w/w), the results show that all the solutions present a first-degree exponential decay trend in which the longer the curing time, the lower the $\mathrm{SW}_{24}$ of the hydrogels, arguably because of the formation of tighter interactions in the material induced by the heat. Of particular interest is the tendency of the three solutions to reach a similar $\mathrm{SW}_{24}$ under a long curing time.

Regarding the humic acids component, given the complexity of their chemistry, in each experiment in which they are employed, it is important to provide either a thorough characterization or a clear reference of their source when a batch from a public supplier is used (which, in our case, was Aldrich CAS 68131-04-4). We deem this critical to enable reproducibility in future in-depth studies, as each humic material may show a specific chemical behavior and a consequent interactivity, which, in turn, may affect the hydrogel properties.

In the degradation analysis experiments, the results showed that, considering the working range of $\mathrm{SW}_{24}$ values and the AHum amount, the synthesis parameters had little influence on the stability of the hydrogels compared to the environmental parameters tested, which appear to be the main factors affecting the degradation of these hydrogels. In this sense, the existing soil organic matter appears to play a major role as deprived soils, featuring starved microbial communities due to the intensely mineralized organics (as testified by the low $\mathrm{C} / \mathrm{N}$ ratios) that were more aggressive in terms of hydrogel attack in comparison to soils richer in organic matter, where the low $\mathrm{pH}$ would also contribute to slowing hydrogel degradation. In addition to those factors, an overriding role was displayed by soil salinity, as in the coastal soil, in which this parameter exerted the highest level of inhibition on hydrogel destabilization. These findings constitute the relevant premises for the design and optimization of suitable hydrogels for agricultural applications to be tailored specifically across ranges of altitude, climate, and pedochemical parameters. The practical uses envisaged include improved gel-assisted seed survival and germination in which the effects of drought can be mitigated using the hydrogel properties to foster a more uniform sowing success. In particular, this can be critical in fields with minimum or no tillage in conservative agriculture in which limited seed burial in soil is involved.

Author Contributions: Conceptualization, G.G. and M.M.; methodology, G.G. and C.T.; validation, A.S. and F.M.; formal analysis, A.S.; investigation, C.T. and G.G.; resources, M.M.; writing-original draft, C.T.; writing-review and editing, S.G., M.M., A.S. and F.M.; visualization, C.T. and A.S.; supervision, M.M.; project administration, S.G. and M.M.; funding acquisition, M.M. All authors have read and agreed to the published version of the manuscript.

Funding: This work was supported by Fondazione Cassa di Risparmio di Padova e Rovigo (Progetto INNOGEL, Progetti di Eccellenza 2017).

Institutional Review Board Statement: Not applicable.

Informed Consent Statement: Not applicable.

Data Availability Statement: All data are available from the authors upon request.

Acknowledgments: We would like to thank Ilaria Piccoli and Carlo Camarotto from the Department of Agronomy, Food, Natural Resources, Animals and Environment, DAFNAE, University of Padua, Legnaro (PD), Italy, Lorenzo Dainese, for the design of the degradation analysis systems; Nicola Vicentini for his help in data analysis; and Valerio Causin from the Department of Chemical Sciences, DiSC, University of Padua, Padova (PD), Italy.

Conflicts of Interest: The authors declare no conflict of interest. 


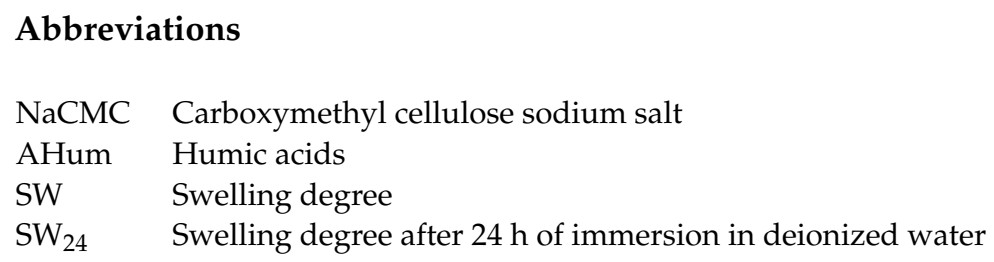

\section{References}

1. Worldometer. Available online: https://www.worldometers.info/world-population/ (accessed on 28 June 2021).

2. Matson, P.A.; Parton, W.J.; Power, A.G.; Swift, M.J. Agricultural intensification and ecosystem properties. Science 1997, 277, 504-509. [CrossRef] [PubMed]

3. Sannino, A.; Demitri, C.; Madaghiele, M. Biodegradable cellulose-based hydrogels: Design and applications. Materials 2009, 2, 353-373. [CrossRef]

4. Peppas, N.A.; Bures, P.; Leobandung, W.; Ichikawa, H. Hydrogels in pharmaceutical formulations. Eur. J. Pharm. Biopharm. 2000, 50, 27-46. [CrossRef]

5. Prasanthi, N.L.; Roy, H.; Jyothi, N.; Vajrapriya, V.S. A Brief Review on Chitosan and Application in Biomedical Field. Am. J. PharmTech Res. 2016, 6, 41-51.

6. Ullah, F.; Bisyrul, M.; Javed, F.; Akil, H. Classification, processing and application of hydrogels: A review. Mater. Sci. Eng. C 2015, 57, 414-433. [CrossRef] [PubMed]

7. Chang, C.; Zhang, L. Cellulose-based hydrogels: Present status and application prospects. Carbohydr. Polym. 2011, 84, 40-53. [CrossRef]

8. Maitra, J.; Shukla, V.K. Cross-linking in Hydrogels-A Review. Am. J. Polym. Sci. 2014, 4, 25-31.

9. Aminabhavi, T.M.; Deshmukh, A.S. Polysaccharide-Based Hydrogels as Biomaterials; Springer International Publishing: Cham, Switzerland, 2016.

10. Heinze, T.; el Seoud, O.A.; Koschella, A. Cellulose Derivatives: Synthesis, Structure, and Properties; Heinze, T., el Seoud, O.A., Koschella, A., Eds.; Springer International Publishing: Cham, Switzerland, 2018; pp. 39-172.

11. Esposito, F.; del Nobile, M.A.; Mensitieri, G.; Nicolais, L. Water sorption in cellulose-based hydrogels. J. Appl. Polym. Sci. 1996, 60, 2403-2407. [CrossRef]

12. Bentonite. Available online: https://bentonite.it/proprieta-bentonite.php (accessed on 14 January 2021).

13. Belchinskaya, L.I.; Novikova, L.A.; Khokhlov, V.Y.; Tkhi, J.L.; Kartel, M.T. Surface Chemistry and Porosity of Natural and Activated Aluminosilicate from Montmorillonite and Clinoptilolite. Хімія, фізика та технологія поверхні 2015, 4, 358-365.

14. Abdullahi, S.L.; Audu, A.A. Comparative Analysis on Chemical Composition of Bentonite Clays Obtained from Ashaka and Tango Deposits in Gombe State, Nigeria. ChemSearch J. 2017, 8, 35-40.

15. Valde, B. Origin and Mineralogy of Clays: Clays and the Environment, 1st ed.; Springer: Berlin, Germany; Heidelberg, Germany, 1995.

16. Mi, J.; Gregorich, E.G.; Xu, S.; Mclaughlin, N.B.; Ma, B.; Liu, J. Field Crops Research Effect of bentonite amendment on soil hydraulic parameters and millet crop performance in a semi-arid region. Field Crop Res. 2017, 212, 107-114. [CrossRef]

17. Canellas, L.P.; Olivares, F.L.; Aguiar, N.O.; Jones, D.L.; Nebbioso, A.; Mazzei, P.; Piccolo, A. Scientia Horticulturae Humic and fulvic acids as biostimulants in horticulture. Sci. Hortic. 2015, 196, 15-27. [CrossRef]

18. Pettit, R.E. Organic matter, humus, humate, humic acid, fulvic acid and humin: Their importance in soil fertility and plant health. CTI Res. 2004, 10, 1-7.

19. Zhou, L.; Monreal, C.M.; Xu, S.; Mclaughlin, N.B.; Zhang, H. Geoderma Effect of bentonite-humic acid application on the improvement of soil structure and maize yield in a sandy soil of a semi-arid region. Geoderma 2019, 338, 269-280. [CrossRef] 